\begin{tabular}{c}
\hline JCEBT, 2 (1) Maret 2018 ISSN 2549-6379 (Print) ISSN 2549-6387 (Online) \\
JCEBT \\
OEournal of Civil Engineering, Building and Transportation) \\
Available online http://ojs.uma.ac.id/index.php/jcebt \\
\hline
\end{tabular}

\title{
Analisa Pengaruh Penambahan Belerang Pada Aspal AC-WC Terhadap Nilai Stabilitas dan Kelelehan Marshall
}

\section{Analysis of the Effect of Sulfur Addition to AC-WC Asphalt on Marshall Stability and Melting Value}

\author{
M. Imam Fadholi Siregar, Marwan Lubis \\ Program Studi Sipil, Fakultas Teknik \\ Universitas Islam Sumatera Utara
}

e-mail : muhammadifadhsiregar@gmail.com

\begin{abstract}
Abstrak
Jalan selalu dibutuhkan sebagai suatu media transportasi, oleh kareana itu dibutuhkan keawetan pada perkerasan jalan. Dalam meningkatkan struktur perkerasan jalan dibutuhkan alternatif bahan untuk dicampur dengan aspal ataupun agregat. Penelitian ini dilakukan di laboratorium PPS3 Balai Besar dengan dasar menggunakan sistem pencampuran aspal panas Asphalt Concrete - Wearing Course (ACWC). Di dalam penelitian ini pengujian dilakukan secara bertahap, yaitu terdiri atas pengujian agregat (kasar, halus dan filler), aspal dan pengujian terhadap campuran, dimana dari pengujian Marshall tersebut didapatkan hasil-hasil yang berupa komponen-komponen Marshall, yaitu stabilitas, flow, dan kemudian dapat dihitung Marshall Quotient-nya. Pengujian dilakukan dengan variasi persentase kadar belerang 5\% dan 10\%. Dari hasil pengujian ini dapat disimpulkan semakin besar penambahan belerang maka nilai stabilitas akan menurun, dan sebaliknya nilai flow akan meningkat.

Kata Kunci : belerang, campuran, flow, stabilitas
\end{abstract}

\begin{abstract}
The road is always needed as a transport medium, by the mindless and required durability of the pavement. In improving the road pavement structure needed an alternative material to be mixed with asphalt or aggregate. This research was conducted in the laboratory PPS3 Great Hall of the base using hot asphalt mixing system Asphalt Concrete - Wearing Course (AC-WC). In this study testing is done in stages, which consists of testing aggregates (coarse, fine and filler), asphalt and testing of the mixture, wherein from Marshall test is obtained results in the form of components Marshall, namely stability, flow, and can then be calculated Marshall Quotient. Testing was done by varying the percentage of sulfur content of 5\% and $10 \%$. From the test results we can conclude the greater the addition of sulfur, the value of stabiliy will decrease, and conversely the value of flow will increase.
\end{abstract}

Keywords : flow, mixed, stability, sulfur

How to Cite: Siregar, M.I.F., Lubis. M. (2018) analisa pengaruh penambahan belerang pada aspal AC-WC terhadap nilai stabilitas dan kelelehan marshall,vol 2,no 1:20-27 


\section{PENDAHULUAN}

Aspal beton sebagai bahan untuk konstruksi jalan sudah lama dikenal dan digunakan secara luas dalam pembuatan jalan. Hal ini disebabkan aspal beton mempunyai beberapa kelebihan. Kemampuannya dalam mendukung beban berat kendaraan yang tinggi dan dapat dibuat dari bahan-bahan lokal yang tersedia dan mempunyai ketahanan yang baik terhadap cuaca. Dewasa ini banyak terjadi kerusakan-kerusakan pada perkerasan beton aspal serperti kerusakan alur dan terjadinya lubang yang lebih dini.

Seiring meningkatnya kebutuhan akan jalan, maka dibutuhkan usaha-usaha untuk meningkatkan kualitas jalan. Upayaupaya yang dilakukan antara lain adalah penggunaan campuran aspal yang baik, yaitu; mempunyai daya lekat yang cukup tinggi, titik lembek yang tinggi (di atas $60 \mathrm{oC})$, dan penetrasi diatas 50 .

Beberapa penelitian telah dicoba untuk meneliti berbagai jenis bahan yang dapat digunakan untuk mencapai sifatsifat aspal yang diinginkan. Penggunaan bahan-bahan tambah ke dalam campuran aspal tergantung pada hasil akhir yang diinginkan. Sebagai contoh; jika diinginkan aspal sebagai bahan pengikat yang berdaya lekat tinggi maka digunakan bahan pengikat yang berdaya lekat tinggi.
Berdasarkan hal tersebut peneliti mencoba untuk melihat pengaruh pada bahan sulfur dalam campuran beraspal. Dengan mengetahui pengaruh sulfur yang ditambah kedalam campuran beraspal maka dapat diperkirakan kelebihan dan kekurangan campuran tersebut.

Tujuan penelitian ini adalah untuk mengetahui apakah penambahan belerang memberikan pengaruh yang signifikan terhadap nilai stabilitas dan kelelehan pada campuran aspal AC-WC.

\section{METODE PENELITIAN}

\section{Bahan Penelitian}

Bahan-bahan yang akan digunakan dalam penelitian ini antara lain :

1. Agregat kasar, diperoleh dari PT. Karya Murni Perkasa di Patumbak.

2. Agregat pengisi (filler) diperoleh dari PT. Karya Murni Perkasa di Patumbak.

3. Agregat halus diperoleh dari PT. Karya Murni Perkasa di Patumbak.

4. Belerang diperoleh dari toko bangunan Jalan Lau Dendang.

5. Aspal menggunakan KASENA dengan penetrasi $60 / 70$.

\section{Peralatan Penelitian}

Alat yang digunakan untuk pemeriksaan aspal antara lain: alat uji penetrasi, alat uji titik lembek, alat uji titik nyala dan titik bakar, alat uji daktilitas, alat uji berat jenis (piknometer dan timbangan), alat uji kelarutan (CCl4). Alat 
uji yang digunakan untuk pemeriksaan agregat antara lain mesin Los Angeles (tes abrasi), saringan standar (yang terdiri dari ukuran 3/4", 1/2", 3/8", \#4, \#8, \#16, \#30, \#50 dan \#200), alat uji kepipihan, alat pengering (oven), timbangan berat, alat uji berat jenis (piknometer, timbangan, pemanas), bak perendam dan tabung sand equivalent. Alat cetak benda uji berbentuk silinder diameter 10,2cm (4inch) dengan tinggi $7,5 \mathrm{~cm}$ (3inch) untuk Marshall standar. Penumbuk yang mempunyai permukaan rata berbentuk silinder dengan diameter $9,8 \mathrm{~cm}$, berat $4,5 \mathrm{~kg}(10 \mathrm{lb})$ dengan tinggi jatuh bebas $45,7 \mathrm{~cm}$ (18inch). Ejektor untuk mengeluarkan benda uji setelah proses pemadatan. Bak perendam yang dilengkapi pengatur suhu. Alat-alat penunjang yang meliputi panci pencampur, kompor pemanas, termometer, kipas angin, sendok pengaduk, kaos tangan anti panas, kain lap, spatula, timbangan dan tip-ex/cat minyak yang digunakan untuk menandai benda uji.

Prosedur Perencanaan Penelitian

Prosedur-prosedur perencanaan penelitian yang dilakuakan dengan tahapan sebagai berikut :

a. Dilakukan penimbangan agregat sesuai dengan persentase pada target gradasi yang diinginkan untuk masing-masing fraksi dengan berat campuran kira-kira 1200 gram untuk diameter 4 inchi, kemudian dilakukan pengeringan campuran agregat tersebut sampai beratnya tetap sampai suhu $( \pm 150)^{\circ} \mathrm{C}$.

b. Dilakukan penimbangan belerang dengan kadar yang sudah direncanakan untuk pencampuran.

c. Dilakukan pemanasan aspal untuk pencampuran pada viskositas kinematic $100 \pm 10$ centistokes. Agar temperatur campuran agregat dan aspal tetap maka pencampuran dilakukan di atas pemanas dan diaduk hingga rata.

d. Setelah temperatur pemadatan tercapai yaitu pada viskositas kinematik $100 \pm 10$ centistokes, maka campuran tersebut dimasukkan ke dalam cetakan yang telah dipanasi pada temperatur 100 hingga 170을 serta bagian bawah cetakan diberi sepotong kertas filter atau kertas lilin (waxed paper) yang telah dipotong sesuai dengan diameter cetakan sambil ditusuk-tusuk dengan spatula sebanyak 15 kali di bagian tepi dan 10 kali di bagian tengah.

e. Pemadatan standar dilakukan dengan pemadat manual dengan jumlah tumbukan 75 kali di bagian sisi atas kemudian dibalik dan sisi bagian bawah juga ditumbuk sebanyak 75 kali.

f. Setelah proses pemadatan selesai benda uji didiamkan agar suhunya 
turun, setelah dingin benda uji dikeluarkan dengan ejektor dan diberi kode, dan di dinginkan selama 24 jam.

g. Setelah 24 jam berlalu benda uji dibersihkan dari kotoran yang menempel dan diukur tinggi benda uji dengan ketelitian $0,1 \mathrm{~mm}$.

h. Kemudian dilakukan uji density untuk mendapatkan berat diudara, berat jenuh dan berat didalam air.

i. Benda uji dikeringkan dengan kain pada permukaan agar kondisi kering.

j. Benda uji direndam dalam bak perendaman pada suhu $\pm 60^{\circ} \mathrm{C}$ selama 24 jam.

k. Setelah itu dilakukan tes Marshall.

l. Benda uji dikeluarkan dari bak perendam, lalu diletakkan tepat di tengah pada bagian bawah kepala penekan kemudian bagian atas kepala diletakkan dengan memasukkan lewat batang penuntun. Setelah pemasangan sudah lengkap maka diletakkan tepat di tengah alat pembebanan. Kemudian arloji kelelehan (flow meter) dipasang pada dudukan di atas salah satu batang penuntun.

m. Kepala penekan dinaikkan hingga menyentuh atas cincin penguji, kemudian diatur kedudukan jarum arloji penekan dan arloji kelelehan pada angka nol. n. Pembebanan dilakukan dengan kecepatan tetap $51 \mathrm{~mm}$ (2 inch) per menit, hingga kegagalan benda uji terjadi yaitu pada saat arloji pembebanan berhenti dan mulai kembali berputar menurun, pada saat itu pula dibuka arloji kelelehan. Titik pembacaan pada saat benda uji mengalami kegagalan adalah merupakan nilai stabilitas Marshall.

o. Setelah pengujian selesai, kepala penekan diambil, bagian atas dibuka dan benda uji dikeluarkan. Waktu yang diperlukan dari saat diangkatnya benda uji dari rendaman air sampai tercapainya beban maksimum tidak boleh melebihi 60 detik.

\section{Pengujian Material Agregat}

Dalam pemilihan bahan agregat diupayakan menjamin tingkat penyerapan air yang paling rendah. Hal itu merupakan antisipasi atas hilangnya material aspal yang terserap oleh agregat. Agregat dapat terdiri atas beberapa fraksi, misalnya fraksi kasar, fraksi medium dan abu batu atau pasir alam. Pada umumnya fraksi kasar dan fraksi medium digolongkan sebagai agregat kasar. Sedangkan untuk abu batu dan pasir alam sebagai agregat halus. Disini peneliti menggunakan material yang telah diuji oleh Laboratorium PSP3 Balai Besar dan siap untuk dilanjutkan ke tahap pencampuran. 


\section{Pengujian Aspal}

Penggunaan aspal Pen 60 disesuaikan dengan kondisi suhu udara rata-rata $25^{\circ} \mathrm{C}$. Metode pengujian aspal sesuai Spesifikasi Umum Bina Marga 2010 dengan mengacu pada SNI 06-6399-2000 dengan ketentuan pada Tabel.

Tabel 1. Ketentuan Aspal

\begin{tabular}{|c|c|c|c|}
\hline $\begin{array}{l}\mathrm{N} \\
\mathrm{O}\end{array}$ & Karakteristik & $\begin{array}{l}\text { Metode } \\
\text { Pengujian }\end{array}$ & $\begin{array}{l}\text { Persyar } \\
\text { atan }\end{array}$ \\
\hline 1 & $\begin{array}{l}\text { Penetrasi; } \quad 25^{\circ} \mathrm{C} \\
(0,1 \mathrm{~mm})\end{array}$ & $\begin{array}{l}\text { SNI 06- } \\
2456-1991\end{array}$ & $60-70$ \\
\hline 2 & $\begin{array}{l}\text { Viskositas } \\
\text { Dinamis } \\
\text { (Pa.s) }\end{array}$ & $\begin{array}{l}\text { SNI } \quad 06- \\
6441-2000\end{array}$ & $\begin{array}{l}160- \\
240\end{array}$ \\
\hline 3 & $\begin{array}{l}\text { Viskositas } \\
\text { Kinematis } 135^{\circ} \mathrm{C} \\
(\mathrm{cSt})\end{array}$ & $\begin{array}{l}\text { SNI 06- } \\
6441-2000\end{array}$ & $\geq 300$ \\
\hline 4 & Titik Lembek $\left({ }^{\circ} \mathrm{C}\right)$ & $\begin{array}{l}\text { SNI } \\
2434: 2011\end{array}$ & $\geq 48$ \\
\hline 5 & $\begin{array}{l}\text { Daktilitas pada } \\
25^{\circ} \mathrm{C},(\mathrm{cm})\end{array}$ & $\begin{array}{l}\text { SNI } \\
2432: 2011\end{array}$ & $\geq 100$ \\
\hline 6 & Titik Nyala $\left({ }^{\circ} \mathrm{C}\right)$ & $\begin{array}{l}\text { SNI } \\
\text { 2433:2011 }\end{array}$ & $\geq 232$ \\
\hline 7 & $\begin{array}{l}\text { Kelarutan dalam } \\
\text { Trichloroethylene } \\
(\%)\end{array}$ & $\begin{array}{l}\text { AASHTO } \\
\text { T44-03 }\end{array}$ & $\geq 99$ \\
\hline 8 & Berat Jenis & $\begin{array}{l}\text { SNI } \\
2441: 2011\end{array}$ & $\geq 1,0$ \\
\hline
\end{tabular}

Sumber : Spesifikasi Umum Bina Marga 2010, Revisi 3, Divisi 6

\section{HASIL DAN PEMBAHASAN}

Hasil Pemeriksaan Agregat

Kualitas agregat dapat diketahui dengan cara pemeriksaan percobaan sehingga diperoleh data laboratorium. Pemeriksaan agregat di laboratorium merupakan pemeriksaan terhadap berat jenis semu agregat kasar dan berat jenis semu agregat halus. Hasil pemeriksaan menunjukkan bahwa agregat yang digunakan telah memenuhi syarat yang di tentukan. Hasil pemeriksaan agregat seperti yang terlihat pada tabel berikut.
Tabel 2. Hasil Pemeriksaan Agregat Kasar (CA) 3/4

\begin{tabular}{|c|c|c|c|c|}
\hline $\begin{array}{l}\mathbf{N} \\
\mathbf{0}\end{array}$ & $\begin{array}{l}\text { Jenis } \\
\text { Pemeriks } \\
\text { aan }\end{array}$ & $\begin{array}{l}\text { Has } \\
\text { il }\end{array}$ & $\begin{array}{l}\text { Spesifik } \\
\text { asi }\end{array}$ & $\begin{array}{l}\text { Keteran } \\
\text { gan }\end{array}$ \\
\hline 1 & $\begin{array}{l}\text { Berat Jenis } \\
\text { Bulk }\end{array}$ & $\begin{array}{l}2.68 \\
7\end{array}$ & $\begin{array}{l}\min .2 .5 \\
\mathrm{gr}\end{array}$ & $\begin{array}{l}\text { Memenu } \\
\text { hi }\end{array}$ \\
\hline 2 & $\begin{array}{l}\text { Permukaa } \\
\text { n SSD }\end{array}$ & $\begin{array}{l}2.69 \\
7\end{array}$ & $\begin{array}{l}\min . \quad 2.5 \\
\mathrm{gr}\end{array}$ & $\begin{array}{l}\text { Memenu } \\
\text { hi }\end{array}$ \\
\hline 3 & $\begin{array}{l}\text { Berat Jenis } \\
\text { Semu }\end{array}$ & $\begin{array}{l}2.71 \\
4\end{array}$ & $\begin{array}{l}\min .2 .5 \\
\mathrm{gr}\end{array}$ & $\begin{array}{l}\text { Memenu } \\
\text { hi }\end{array}$ \\
\hline 4 & $\begin{array}{l}\text { Penyerapa } \\
\mathrm{n}\end{array}$ & $\begin{array}{l}1.18 \\
6 \\
\end{array}$ & $\begin{array}{l}\text { maks. } 3 \\
\%\end{array}$ & $\begin{array}{l}\text { Memenu } \\
\text { hi }\end{array}$ \\
\hline
\end{tabular}

Tabel 3. Hasil Pemeriksaan Agregat Medium (MA) $1 / 2$

\begin{tabular}{c|l|c|c|c}
\hline No & Jenis & Hasil & Spesifikasi & Keterangan \\
& Pemeriksaan & & & \\
\hline 1 & Berat Jenis Bulk & 2.683 & min. 2,5 gr & Memenuhi \\
2 & Permukaan SSD & 2.696 & min. 2,5 gr & Memenuhi \\
3 & Berat Jenis & 2.720 & min. 2.5 gr & Memenuhi \\
& Semu & & & \\
4 & Penyerapan & 0.514 & maks. 3\% & Memenuhi \\
\hline
\end{tabular}

Tabel 4. Hasil Pemeriksaan Abu Batu

\begin{tabular}{l|l|l|l|l}
\hline No & $\begin{array}{l}\text { Jenis } \\
\text { Pemeriksaan }\end{array}$ & Hasil & Spesifikasi & Keterangan \\
\hline 1 & Berat Jenis Bulk & 2.532 & min. 2,5 gr & Memenuhi \\
2 & Permukaan SSD & 2.591 & min. 2,5 gr & Memenuhi \\
& Berat Jenis & 2.691 & min. 2.5 gr & Memenuhi \\
3 & Semu & & maks. 3\% & Memenuhi \\
4 & Penyerapan & 2.277 & & \\
\hline
\end{tabular}

Tabel 5. Hasil Pemeriksaan Pasir

\begin{tabular}{|c|c|c|c|c|}
\hline $\begin{array}{l}\mathbf{N} \\
\mathbf{o}\end{array}$ & $\begin{array}{l}\text { Jenis } \\
\text { Pemeriks } \\
\text { aan }\end{array}$ & $\begin{array}{l}\text { Has } \\
\text { il }\end{array}$ & $\begin{array}{l}\text { Spesifik } \\
\text { asi }\end{array}$ & $\begin{array}{l}\text { Keterang } \\
\text { an }\end{array}$ \\
\hline 1 & $\begin{array}{l}\text { Berat Jenis } \\
\text { Bulk }\end{array}$ & $\begin{array}{l}2.53 \\
2\end{array}$ & $\begin{array}{l}\min . \quad 2,5 \\
\text { gr }\end{array}$ & $\begin{array}{l}\text { Memenu } \\
\text { hi }\end{array}$ \\
\hline 2 & $\begin{array}{l}\text { Permukaa } \\
\text { n SSD }\end{array}$ & $\begin{array}{l}2.65 \\
1\end{array}$ & $\begin{array}{l}\min . \quad 2,5 \\
\text { gr }\end{array}$ & $\begin{array}{l}\text { Memenu } \\
\text { hi }\end{array}$ \\
\hline 3 & $\begin{array}{l}\text { Berat Jenis } \\
\text { Semu }\end{array}$ & $\begin{array}{l}2.87 \\
2\end{array}$ & $\min _{\mathrm{gr}} \quad 2.5$ & $\begin{array}{l}\text { Memenu } \\
\text { hi }\end{array}$ \\
\hline 4 & $\begin{array}{l}\text { Penyerapa } \\
\mathrm{n}\end{array}$ & $\begin{array}{l}4.67 \\
1\end{array}$ & $\begin{array}{l}\text { maks. } 3 \\
\%\end{array}$ & Melebihi \\
\hline
\end{tabular}

Sumber : Tabel 2-5 Hasil Penelitian

\section{Hasil Pemeriksaan Aspal}

Data hasil pemeriksaan aspal penetrasi 60/70 merupakan data hasil pengujian laboratorium. Dari hasil pengujian yang telah dilakukan, aspal mempunyai karakteristik yang telah memenuhi spesifikasi Petunjuk Lapis 
Aspal Beton sesuai Spesifikasi Umum Bina Marga 2010 Revisi 3 Divisi 6. Hasil pemeriksaan aspal seperti yang terlihat pada Tabel dibawah.

Tabel 6. Hasil Pemeriksaan Aspal

\begin{tabular}{|c|c|c|c|c|c|c|}
\hline \multirow{3}{*}{$\begin{array}{l}\mathbf{N} \\
\mathbf{o}\end{array}$} & \multirow[t]{3}{*}{$\begin{array}{l}\text { PENG } \\
\text { UJIAN }\end{array}$} & \multirow{3}{*}{$\begin{array}{l}\text { HAS } \\
\text { IL } \\
\text { PEN } \\
\text { GUJI } \\
\text { AN }\end{array}$} & \multicolumn{3}{|c|}{$\begin{array}{l}\text { SPESIFIK } \\
\text { ASI }\end{array}$} & \multirow[t]{2}{*}{$\begin{array}{l}\text { SATU } \\
\text { AN }\end{array}$} \\
\hline & & & \multirow{2}{*}{\multicolumn{3}{|c|}{$\begin{array}{l}\text { MAX } \\
\text { MIN }\end{array}$}} & \\
\hline & & & & & & \\
\hline 1 & $\begin{array}{l}\text { Penetra } \\
\text { si pada } \\
25^{0} \mathrm{C}\end{array}$ & 66 & 70 & - & $\begin{array}{l}6 \\
0\end{array}$ & \\
\hline 2 & $\begin{array}{l}\text { Titik } \\
\text { Lembe } \\
\text { k }\end{array}$ & 48 & & - & $\begin{array}{l}4 \\
8\end{array}$ & \\
\hline 3 & $\begin{array}{l}\text { Daktilit } \\
\text { as pada } \\
25^{0} \mathrm{C}\end{array}$ & 150 & & - & $\begin{array}{l}10 \\
0\end{array}$ & \\
\hline 4 & $\begin{array}{l}\text { Titik } \\
\text { Nyala }\end{array}$ & 276 & & - & $\begin{array}{l}23 \\
2\end{array}$ & \\
\hline 5 & $\begin{array}{l}\text { Berat } \\
\text { Jenis }\end{array}$ & 1,058 & & - & 1 & \\
\hline 6 & $\begin{array}{l}\text { Kehilan } \\
\text { gan } \\
\text { Berat }\end{array}$ & $\begin{array}{l}0,02 \\
9\end{array}$ & & - & $\begin{array}{l}0 \\
8\end{array}$ & \\
\hline 7 & $\begin{array}{l}\text { Penetra } \\
\text { si } \\
\text { setelah } \\
\text { kehilan } \\
\text { gan } \\
\text { berat }\end{array}$ & 62,2 & & - & 54 & \\
\hline
\end{tabular}

Sumber : Data PSP3 Balai Besar

Dari hasil pengujian aspal seperti pada Tabel 6 diatas merupakan hasil pengujian yang dilakukan oleh Laboratorium PSP3 Balai Besar. Selain itu penyimpanan material yang benar juga merupakan salah satu keberhasilan dalam seluruh hasil pengujian aspal agar memenuhi standart spesifikasi.

Hasil Pemeriksaan dan Pengujian Marshall

Proses pengujian Marshall dapat dilakukan setelah seluruh persyaratan material, berat jenis, penyerapan aspal dan perkiraan kadar aspal rencana telah terpenuhi. Penulis hanya menguji stabilitas dan kelelehan marshall.

Masing-masing benda uji setiap kadar aspal yang berbeda adalah tiga benda uji. Sedangkan hasil pengujiannya dapat dilihat pada Tabel 7. di bawah ini.

Tabel 7. Hasil Pengujian Marshall Pada Kadar Aspal Rencana dengan 2X75 Tumbukan

\begin{tabular}{|c|c|c|c|c|}
\hline No. & $\begin{array}{l}\text { Kadar } \\
\text { Aspal } \\
5(\%)\end{array}$ & $\begin{array}{l}\text { Bulk } \\
\text { Density } \\
\text { (gr) }\end{array}$ & $\begin{array}{l}\text { Stability } \\
(\mathrm{kg})\end{array}$ & $\begin{array}{l}\text { Flow } \\
(\mathrm{mm})\end{array}$ \\
\hline 1 & \multirow{3}{*}{5} & 2.387 & 1.562 & 2,56 \\
\hline 2 & & 2.456 & 1.480 & 2,79 \\
\hline 3 & & 2.371 & 1.507 & 2,76 \\
\hline 1 & \multirow{3}{*}{$5 \cdot 5$} & 2.405 & 1.397 & 3,15 \\
\hline 2 & & 2.391 & 1.370 & 3,31 \\
\hline 3 & & 2.411 & 1.425 & 3,27 \\
\hline 1 & \multirow{3}{*}{6} & 2.359 & 1.288 & 3,65 \\
\hline 2 & & 2.365 & 1.288 & 3,79 \\
\hline 3 & & 2.367 & 1.233 & 3,77 \\
\hline 1 & \multirow{3}{*}{6.5} & 2.366 & 1.151 & 4,23 \\
\hline 2 & & 2.811 & 1.206 & 4,1 \\
\hline 3 & & 2.765 & 1.178 & 4,12 \\
\hline 1 & \multirow{3}{*}{7} & 2.356 & 1.096 & 4,55 \\
\hline 2 & & 2.395 & 1.123 & 4,41 \\
\hline 3 & & 2.567 & 1.041 & 4,42 \\
\hline
\end{tabular}

(a)

\begin{tabular}{|c|c|c|c|c|}
\hline No. & $\begin{array}{l}\text { Kadar Aspal } \\
10(\%)\end{array}$ & $\begin{array}{l}\text { Bulk } \\
\text { Density } \\
\text { (gr) }\end{array}$ & $\begin{array}{l}\text { Stability } \\
(\mathrm{kg})\end{array}$ & $\begin{array}{l}\text { Flow } \\
(\mathrm{mm})\end{array}$ \\
\hline 1 & \multirow{3}{*}{5} & 2.343 & 1.343 & 3,79 \\
\hline 2 & & 2.453 & 1.288 & 3,87 \\
\hline 3 & & 2.343 & 1.288 & 3,92 \\
\hline 1 & \multirow{3}{*}{5.5} & 2.472 & 1.151 & 4,19 \\
\hline 2 & & 2.392 & 1.151 & 4,02 \\
\hline 3 & & 2.463 & 1.206 & 4,11 \\
\hline
\end{tabular}




\begin{tabular}{|c|c|c|c|c|}
\hline 1 & \multirow{3}{*}{6} & 2.345 & 1.069 & 4,41 \\
\hline 2 & & 2.390 & 1.014 & 4,32 \\
\hline 3 & & 2.330 & 1.096 & 4,29 \\
\hline 1 & \multirow{3}{*}{6.5} & 2.366 & 877 & 4,52 \\
\hline 2 & & 2.818 & 904 & 4,51 \\
\hline 3 & & 2.745 & 959 & 4,69 \\
\hline 1 & \multirow{3}{*}{7} & 2.332 & 795 & 4,89 \\
\hline 2 & & 2.383 & 822 & 4,87 \\
\hline 3 & & 2.573 & 822 & 4,91 \\
\hline
\end{tabular}

(b)

Sumber : Hasil Penelitian

Tabel 8. Hasil Penelitian

\begin{tabular}{|l|l|l|l|l|}
\hline \multicolumn{5}{|l|}{ Rata-rata } \\
\hline $\begin{array}{l}\text { Kadar } \\
\text { Belerang } \\
5 \%\end{array}$ & $\begin{array}{l}\text { Bulk } \\
\text { Density } \\
(\mathrm{gr})\end{array}$ & $\begin{array}{l}\text { Stability } \\
(\mathrm{kg})\end{array}$ & $\begin{array}{l}\text { Flow } \\
(\mathrm{mm})\end{array}$ & $\begin{array}{l}\text { Marshall } \\
\text { Quotient } \\
(\mathrm{kg} / \mathrm{mm})\end{array}$ \\
\hline 5 & 2.405 & 1.516 & 2,7 & 562 \\
\hline 5,5 & 2.402 & 1.397 & 3,24 & 431 \\
\hline 6 & 2.364 & 1.270 & 3,74 & 339 \\
\hline 6,5 & 2.647 & 1.178 & 4,15 & 284 \\
\hline 7 & 2.439 & 1.087 & 4,46 & 244 \\
\hline
\end{tabular}

(a)

\begin{tabular}{|l|l|l|l|l|}
\hline \multicolumn{5}{|l|}{ Rata-rata } \\
\hline $\begin{array}{l}\text { Kadar } \\
\text { Belerang } \\
\mathbf{1 0} \%\end{array}$ & $\begin{array}{l}\text { Bulk } \\
\text { Density } \\
(\mathrm{gr})\end{array}$ & $\begin{array}{l}\text { Stability } \\
(\mathrm{kg})\end{array}$ & $\begin{array}{l}\text { Flow } \\
(\mathrm{mm})\end{array}$ & $\begin{array}{l}\text { Marshall } \\
\text { Quotient } \\
(\mathrm{kg} / \mathrm{mm})\end{array}$ \\
\hline 5 & 2.380 & 1.306 & 3,86 & 338 \\
\hline 5,5 & 2.442 & 1.169 & 4,11 & 284 \\
\hline 6 & 2.355 & 1.059 & 4,34 & 244 \\
\hline 6,5 & 2.643 & 913 & 4,57 & 200 \\
\hline 7 & 2.429 & 813 & 4,89 & 166 \\
\hline
\end{tabular}

(b)

Sumber : Hasil Penelitian

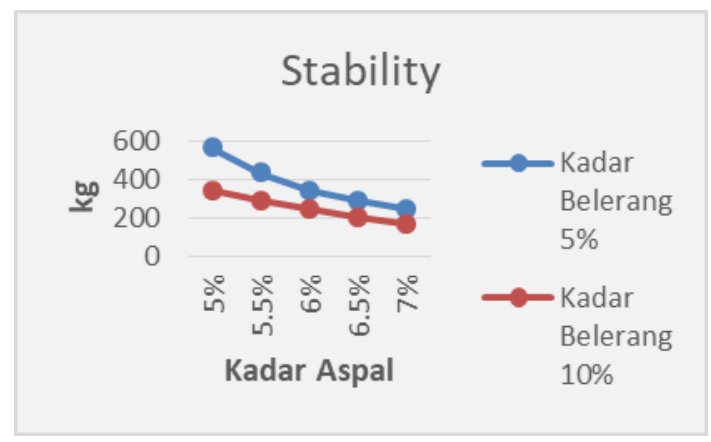

Grafik 1. Stabilitas

Sumber : Hasil Penelitian

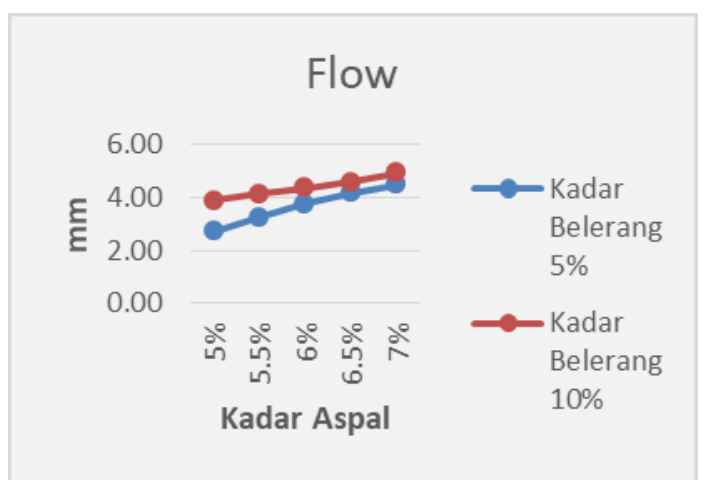

Grafik 2. Kelelehan (flow)

Sumber : Hasil Penelitian

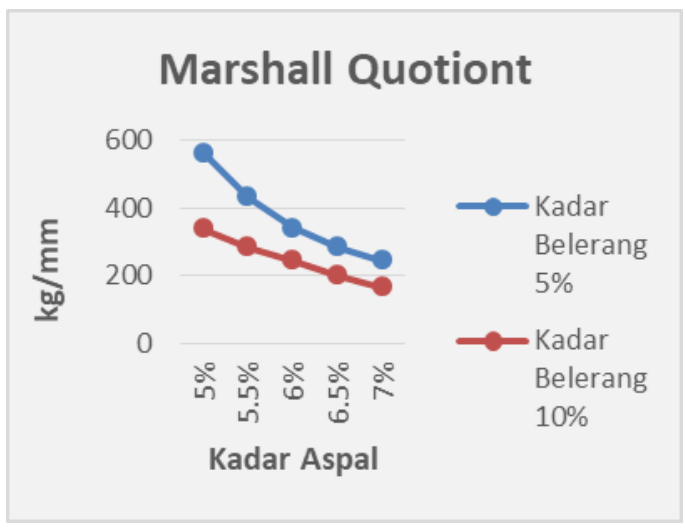

Grafik 3. Marshall Quotiont

Sumber : Hasil Penelitian

\section{SIMPULAN}

Dari hasil penelitian benda uji yang telah ditambahkan kadar belerang, penambahan belerang dan stabilitas berbanding terbalik. Semakin tinggi kadar belerang dan aspal, semakin rendah nilai stabilitasnya, penambahan belerang berbanding lurus terhadap nilai kelelehan. Semakin tinggi kadar belerang dan aspal maka semakin tinggi nilai kelelehannya, dan pada pencampuran belerang 10\% pada aspal 7\% nilai Marshall Quotient tidak memenuhi persyaratan yg jatuh pada 
$166 \mathrm{~kg} / \mathrm{mm}$. Nilai minimal Marshall

Quotient adalah $200(\mathrm{Kg} / \mathrm{mm})$.

\section{DAFTAR PUSTAKA}

Anas Tahir, Jurnal SMARTek, Vol. 7, No. 4, Nopember 2009: 256 - 278, Karakteristik Campuran Beton Aspal (Ac-Wc) Dengan Menggunakan Variasi Kadar Filler Abu Terbang Batu Bara.

Badan Standardisai Nasional BSN, ICS 91.100.10, SNI 15-2049-2004, Semen Portland.

Departemen Pekerjaan Umum Direktorat Jenderal Bina Marga, Pemanfaatan Asbuton Buku 3 Campuran Beraspal Panas dengan Asbuton Olahan, No: 001 - 03 / BM / 2006.

Departemen Pekerjaan Umum Direktorat Jendral Bina Marga 2009, Spesifikasi Khusus Seksi 5.7 Lapis Pondasi Pasir Aspal.

Hadi Ali, Jurnal Rekayasa Vol. 15 No. 1, April 2011 Karakteristik Campuran Asphalt ConcreteWearing Course (Ac-Wc) Dengan Penggunaan Abu Vulkanik Dan Abu Batu Sebagai Filler.

Mochamad Shamier, Evaluasi Karakteristik Campuran Laston Ac - Wc, 2008.

Proyek Jalan Teori \& Praktek, Arthur Wignall Edisi Keempat, 2003.

Rian Putrowijoyo, Kajian Laboratorium Sifat Marshall Dan Durabilitas Asphalt Concrete Wearing Course (Ac-Wc) Dengan Membandingkan Penggunaan Antara Semen Portland dan Abu Batu Sebagai Filler, 2006.

Spesifikasi Umum Bina Marga 2010, Revisi 3, Divisi 6 Perkerasan Aspal.

Vebby Permatasari Subono, The Marshall Characteristics of Asphalt Concrete (AC) Mix with Merapi Volcanic Ash Filler, 2011. 